\title{
Governança global, regulamentação flexível e os ensaios clínicos na medicina regenerativa no Reino Unido e na Uniâo Europeia
}

\section{$\mid{ }^{1}$ Liliana Acero |}

Resumo: A medicina regenerativa encontra-se em fase de desenvolvimento dos ensaios clínicos em terapias celulares (TC), na sua manufatura e na sua adoção gradual dentro dos sistemas de saúde. Entretanto, há uma série de lacunas e contradiçóes na governança e regulamentação na área e o objetivo principal deste artigo é sua discussão dentro das tendências globais, já que esses processos afetam de modo substantivo a saúde coletiva global e encontram-se ainda escassamente resolvidos. $\mathrm{O}$ texto foca nos processos prevalentes nos ensaios clínicos com TC em duas lideranças internacionais, o Reino Unido e a União Europeia, utilizando a análise bibliográfica e de conteúdo. $\mathrm{O}$ texto conclui com uma discussão das principais vantagens e desvantagens para a saúde coletiva global da transição de um modelo científico de comprovação das novas terapias celulares para, eventualmente, outro baseado na inovação médica ou clínica. O último procede desde a fase pré-clínica com animais à aplicação das novas terapias a grupos pequenos de pacientes e, logo a seguir, a sua inserção no mercado. Muitas vezes, esse modelo se associa a flexibilidades regulatórias, a serem ilustradas no artigo, e especialmente desenhadas para aumentar a rapidez no desenvolvimento e aplicação das terapias.

> Palavras-chave: terapia celular; ensaios clínicos; governança; políticas internacionais; medicina regenerativa; regulamentação flexível.

\author{
'Instituto de Economia, \\ Universidade Federal do Rio de \\ Janeiro. Rio de Janeiro-RJ, Brasil \\ (lilianaacero2009@gmail.com). \\ ORCID: 0000-0002-5460-3363
}

Recebido em: 06/02/2019 Aprovado em:19/02/2020 Revisado em: 15/10/2020 


\section{Introdução}

A medicina regenerativa constitui uma mudança do paradigma médico convencional para um novo paradigma, que procura a regeneraçáo do organismo em nível celular ou tecidual (MASON; DUNNILL, 2008, p. 3). Encontra-se em fase do desenvolvimento dos ensaios clínicos em medicinas e terapias celulares (TC), na sua manufatura e na sua adoção gradual nos sistemas de saúde em nível global. ${ }^{1}$ Nessa expansão, existe ainda uma série de importantes lacunas e contradiçôes de governança e regulamentação que influi e é influída pela inovação (MCMAHON; THORSTEINSDOTTIR, 2013).

O objetivo principal deste artigo é discutir a construção das tendências globais na regulamentação e na governança na medicina regenerativa. Esses processos afetam de modo substantivo à saúde coletiva global, e podem vir a afetá-la ainda mais, dependendo da evoluçáo das tendências recentes. $\mathrm{O}$ interesse no estudo dos impactos potenciais de diferentes escolhas regulatórias na saúde coletiva global baseia-se em aspectos éticos, econômicos, sociais e de política pública escassamente resolvidos ainda, em uma fase em que se pretende a inserção, a curto prazo, das TC no mercado de saúde. O texto foca nos processos prevalentes nos ensaios clínicos com TC em duas lideranças internacionais, o Reino Unido (RU) e a União Europeia (UE).

Trata-se de um estudo qualitativo, no qual se utiliza a análise bibliográfica e de conteúdo como ferramentas metodológicas principais, e focadas nas seguintes perguntas: quais articulaçôes de novas formas de regulação e governança estão surgindo na área? Que características apresentam os ensaios clínicos e a sua regulação? Qual a importância das mudanças atuais para a saúde coletiva?

Para a pesquisa de contexto no RU e na UE - base do artigo -, foi realizado um levantamento de informaçóes em três etapas que, ainda que não abranja o universo das instituiçôes envolvidas, pode vir a resultar bastante representativo:

- mapeamento dos relatórios recentes de políticas no RU e de resenhas selecionadas nas revistas especializadas, para delimitar os eventos principais na dinâmica regulatória e de governança;

- consultas nos arquivos de centros científicos nacionais e internacionais, organizaçôes privadas influentes e trabalhos jornalísticos para a identificação de narrativas sociais recorrentes e divergentes;

- levantamento de dados junto a arquivos de agências de regulamentação da UE e de organizaçóes da sociedade civil europeia. 
Os critérios da sistematização dos conteúdos nos textos selecionados incluem: principais eixos em políticas, instituiçóes, normas e açóes, assim como o tipo de representaçôes sociais e de participação na governança dos diferentes grupos de interesse. $\mathrm{O}$ caminho de pesquisa escolhido permite apresentar um panorama abrangente que delimita as características gerais, diferenças, semelhanças e peculiaridades dos contextos em estudo em relação ao assunto selecionado.

\section{A construção global da regulamentação}

$\mathrm{Na}$ construção da regulamentação, as visóes dos atores criam patamares que configuram a produção, acesso e uso dos serviços e produtos, através de um processo de negociação dinâmica entre diferentes entendimentos que definem, o que é "bom", "desejável” e "possível” (JASANOFF; KIM, 2009, p. 120). Coalizôes de atores sociais projetam futuros alternativos com base nesses imaginários sociotécnicos, que se concretizam em instrumentos, regras e formas de intervenção (VAN ZWANENBERG et al., 2011).

O desenvolvimento da medicina regenerativa se depara com a inadequação dos marcos de referência tradicionais às características biológicas das células tronco (CT): o fato de que são "vida" e produzem resultados que mudam durante seu desenvolvimento. A segurança e eficácia no seu uso depende, em geral, do tipo de CT utilizadas e de seu grau de manipulação. O marco regulatório inicial utilizado na terapia celular (TC) foi desenvolvido para os ensaios clínicos randomizados e controlados e a aprovação das drogas farmacêuticas convencionais, que resultam em um protocolo de serviço ou em um produto comercial.

Desde o ano de 2010, profissionais e formuladores de política pública relevantes chegaram a um acordo global de que alguns procedimentos e riscos para os pacientes em relação às TC requeriam novas definiçôes técnicas e marcos de referência normativos. Propostas internacionais de, por exemplo, o Banco Internacional de Células Tronco (ISCB) e o Foro Internacional de Células Tronco (ISCF) - duas instituiçôes do RU - sobre a estandardização dos procedimentos técnicos para a derivação de células, linhagens, culturas e veículos de transporte das CT no organismo humano (ICSI 1, 2 e 3) têm gerado amplo consenso nos países participantes (WEBSTER; ERIKSSON, 2009). Essas iniciativas também constituem uma resposta à proliferação de intervençôes com CT experimentais e sem certeza de acreditação (MCMAHON, 2014). 
Em relação aos ensaios clínicos com TC, no início, predominaram duas posiçôes. A primeira representada, por exemplo, em EUA pelos National Institute of Health e pela International Society for Stem Cell Research do RU, é que os produtos medicinais de base celular devem poucas vezes ser desenvolvidos fora do processo dos ensaios clínicos formais (NIH, 2009; ISSCR, 2016). Por outro lado, linhasguia relevantes de outras associaçóes internacionais, p. ex. International Cellular Medicine Society (ICMS, 2011) e International Society for Cellular Therapy (ISCT, 2015), têm argumentado a favor de aplicações da TC fora do sistema dos ensaios clínicos convencionais.

Encontra-se, em nível global, uma grande variedade de tipos de regulamentação da medicina regenerativa que funciona dentro de duas dinâmicas principais: a) Intentos de harmonização; e b) Processos de diversificação (VAN ZWANENBERG et al., 2011). No primeiro caso, o motor central para a adoção da regulamentação seria a possibilidade dos diferentes países de participar nas colaboraçóes internacionais de $\mathrm{P} \& \mathrm{D}$ e dos ensaios clínicos, liderados pelos EUA e a UE. A harmonização baseia-se no modelo da indústria farmacêutica para o desenvolvimento de drogas e tem por standard de ouro a medicina baseada na evidência e os ensaios convencionais; um modelo científico convencional de comprovação. Nela se pretende uma adaptação dos processos locais de regulamentação às normas desenvolvidas pela elite global na área (SLEEBOOM FAULKNER et al., 2016). Por um lado, possibilitam-se assim as colaboraçôes internacionais e a visibilidade na área, em especial, para os países emergentes (PE), mas por outro, aumentam-se os custos de produçâo das terapias e se diminui o acesso para a maioria da população.

Outro tipo de intento de harmonizaçáo tem sido a liderada pelos bancos de células e linhagens, com a estandardização das práticas científicas por instituiçôes, como são o ISSCR, o ISCF e a Universidade de Massachussetts. Pretende-se complementar o papel dos bancos nacionais de CT, em proliferação, uniformizar em um único portal os registros das informaçóes e interligar os dados e os bancos para facilitar a colaboração internacional. Ainda se desconhece se mediante esses esforços se conseguirá desenvolver um marco referencial global uniforme (KOPPERS; ISASI, 2010).

A segunda tendência regulatória tem sido chamada da "pluralidade de modelos" ou da "política de álter-estandardização"; uma forma de governança que renegocia nas fronteiras das diretrizes, revisôes, acreditaçôes e práticas dominantes globais 
e onde os tratamentos clínicos experimentais são reordenados, estandardizados e adquirem maior transparência. Esse modelo tem sido analisado, às vezes, como um modo de resistência a uma legalidade hegemônica e instituída bottom up (ROSEMANN, 2014). Essas políticas respondem, também, à demanda de pacientes e cidadãos que exigem o "direito de provar as medicinas" e baseia-se em um modelo clínico ou médico, no qual se pulam passos de comprovação dos cinco tradicionais, e procede-se: desde os estudos pré-clínicos em animais aos ensaios clínicos em pequenos grupos de pacientes e direito a seguir, à aprovação clínica das terapias. Mas nesse modelo os pacientes seriam responsáveis conjuntos dos custos das TC e das suas consequências para a saúde. Desse modo, também tendem a diminuir os custos dos ensaios clínicos e a aumentar o acesso em estágios iniciais as intervençôes não totalmente comprovadas. Em geral, a diversificação normativa foi iniciada pelos países asiáticos, em especial, a China e a Índia, mas existem indícios da sua gradual aplicação nos EUA e nos países da UE (ROSEMANN, 2013).

Tem-se encontrado diferentes tipos de tensóes ao interior dos dois modelos de regulamentação descritos, por exemplo, conflitos entre: a) a integração internacional versus a inovação e as oportunidades de negócios em nível local; b) o desenvolvimento e acesso rápido às novas medicinas versus o teste sistemático de seus riscos e eficácia; c) o desenvolvimento de medicina a preços razoáveis versus o ganho corporativo excessivo; e d) o controle regulatório liderado pelo Estado versus as demandas sociais de desregulação (VAN ZWANENBERG et al., 2011).

\section{As especificidades dos ensaios clínicos}

$\mathrm{Na}$ medicina regenerativa, podem se detectar dois tipos de modelos técnicos de ensaios clínicos: aqueles que se enquadram na inovação médica ou clínica versus aqueles que utilizam as CT para testar as drogas. Os primeiros podem ser ensaios autólogos ou alógenos. Os autólogos são terapias personalizadas realizadas nos hospitais, envolvendo o uso das CT do mesmo paciente que são transportadas de um sítio corporal a outro, como nos transplantes do sangue da medula óssea para a terapia coronária. Em geral, essas TC apresentam uma longa evolução histórica na sua aplicação e, desse modo, seus efeitos são mais bem conhecidos e controláveis. Apesar disso, ainda existem contradiçóes entre os especialistas em relação à definição da forma, o lugar e o veículo mais eficazes para sua administração aos pacientes (MARTIN et al., 2008). 
Os ensaios clínicos alógenos seguem a trajetória de inovação tradicional da indústria farmacêutica, ou seja, a manufatura de um produto estandardizado, com o uso de tecido doado por pessoa(s) diferente(s) aos pacientes envolvidos (FOLEY et al., 2011). Os produtos desses ensaios são comercializados, em geral, por empresas privadas e requerem maior nível de escrutínio regulatório, do que aquele habitual nos ensaios autólogos.

$\mathrm{Na}$ Europa, o controle dos ensaios clínicos corresponde à Agência Europeia de Medicinas (EMA) e funciona segundo as Diretivas sobre os Produtos Medicinais das Terapias Avançadas (Advanced Therapy Medicinal Products - ATMP) do ano de 2007, para as medicinas para uso humano baseadas em células, genes e tecido. O ATMP é um sistema de aprovação de mercado centralizado, para todos os produtos gerados industrialmente ou que passaram por algum processo industrial, abrindo assim o caminho para sua inclusão no sistema de proteção da propriedade intelectual (HOGARTH; SALTER, 2010).

Em geral, esses produtos medicinais são desenvolvidos por acadêmicos, pequenas e médias empresas (PME), associaçóes de caridade e hospitais locais - visto que na UE as grandes empresas farmacêuticas seriam responsáveis, por exemplo, por apenas 2\% desses produtos em 2012 (MACIULAITIS et al., 2012). Os requisitos do controle centralizado são, às vezes, muito exigentes para o tipo de produtores principais, de pequeno tamanho, ainda que as infraestruturas clínicas nacionais sejam em geral públicas.

As diretivas normativas da UE são aplicadas no RU pela Agência Regulatória de Medicinas e Produtos para a Saúde (MHRA) que regula as medicinas, os dispositivos médicos e o sangue para transfusóes. Mas o RU mantém algum nível de flexibilidade em nível nacional na reformulação das regras europeias e, ainda em alguns casos, tem desenvolvido formas de regulamentação pioneiras que, posteriormente, foram incluídas no marco normativo da UE.

A necessidade de escrutínio regulatório mais detalhado e contínuo para a TC experimental com células alógenas têm múltiplas causas. Ainda que as CT e as linhagens sejam fabricadas in vitro, elas requerem de uma grande estandardizaçáo, que inclui o controle e documentação do processo de gênesis das células de base. Além disso, como as linhagens são manipuladas várias vezes durante o processo de manufatura do produto, em cada etapa elas podem mudar as suas características. Por essa razão, é necessário um seguimento documentado ao longo do processo 
da sua utilização, assim como, na etapa da sua administração aos pacientes (WEBSTER; HADDAD; WALDBY, 2011).

Existem numerosos riscos ao paciente nestas TC, entre outros, o da translocação das células, da migraçáo dentro do organismo do sítio assinado a outra(s) parte(s) do corpo e da formação de colônias inespecíficas. Há uma grande diferença nas TC e sua "materialidade mutável", em relaçâo à administração de um medicamento convencional, onde o médico pode adequar as dosagens ao paciente individual para prevenir a sua rejeição ou os efeitos adversos. Os "desconhecidos", no caso das medicinas regenerativas, excedem a avaliação tradicional.

A população de pacientes dos ensaios clínicos alógenos também é completamente diferente à dos ensaios convencionais. Primeiro, os pacientes desses ensaios não podem ser voluntários saudáveis, em especial, pelos riscos imprevisíveis associados. Segundo, os pacientes recrutados devem ter a capacidade de consentimento e uma estabilidade biológica e física considerável para minimizar possíveis efeitos adversos. Devem também estar disponíveis para um seguimento ao longo prazo dos efeitos do tratamento. Ou seja, se excluem os pacientes de idades avançadas, aqueles com capacidades diferenciais e os que apresentam outras doenças associadas - habituais dentre os pacientes com intervençôes de CT autólogas. Nos ensaios alógenos, também as mulheres são excluídas, pois se desconhece como a potencial toxicidade das CT pode afetar sua capacidade reprodutiva.

Tudo isto leva a que o processo de recrutamento de pacientes seja mais trabalhoso e de alto custo. Além disso, a codificação permanente das linhagens também é dificultosa, já que elas são entidades vivas e sujeitas a mudanças nem tudo controláveis. A preocupação com a qualidade na área tem aumentado também pela existência de mortes e lesôes na aplicação de tratamentos celulares não autorizados na UE (EUROPEAN MEDICINES AGENCY, 2010).

Estima-se que, entre 2004 e 2010, existiam pelo menos 318 ensaios clínicos na medicina regenerativa na Europa, dos quais $78 \%$ corresponderiam a produtos medicinais de base celular (BLASIMME; RIAL-SEBBAG, 2013) - uma proporção aproximada de $13 \%$ dos ensaios clínicos na área registrados na plataforma da Organização Mundial da Saúde em 2009 (ISASI, 2009). Mas até 2016, apenas oito desses produtos tinham conseguido autorização da EMA na categoria de ATMP (CORBETT et al., 2017). 


\section{A regulação dos ensaios clínicos no RU e na UE}

Nas últimas décadas, detecta-se grande desconforto na comunidade científica internacional e nas empresas em relação à complexidade normativa e à demora na aprovação dos ensaios em TC. Por exemplo, em 2012, os reguladores estimavam uma média de dois anos para a aprovação de um ensaio clínico, fase II ou III no RU, e de até quatro anos nos EUA. No RU, esse período parece ter se reduzido apenas a 18 meses, uns anos após a criação da agência de regulação atual dos ensaios: a Autoridade em Pesquisas da Saúde (HRA).

A nova agência surge da junção de duas instituições prévias, a Autoridade de Fertilização e Embriologia Humana (HFEA), que funciona desde os anos 80s e dedica-se à regulação da reprodução assistida e do uso de embriôes humanos e híbridos (animal/humanos) em pesquisa, e a Autoridade em Tecidos (HTA), do ano de 2005, que regula o uso de tecidos e genes humanos. A HRA, fundada em 2012, tanto para a aprovação ética como técnica dos ensaios clínicos, velaria por todo tipo de pesquisa em humanos, pela transparência da informação pública dos resultados e do bem-estar dos pacientes (O'DOWD, 2013). A centralização das autorizaçôes na HRA tem resultado muito controverso, porque através dessa medida, se atribui autoridade científica e administrativa única a um espaço regulatório não legislativo, e se reduzem as alternativas plurais de governança dos novos produtos (BERMAN; SCHIFF, 2007).

O sistema europeu de ensaios clínicos da medicina regenerativa também tem sido muito questionado pelo setor acadêmico, devido a seu desenho moldado nos ensaios clínicos comerciais e o requisito de um único responsável institucional por ensaio (HOEY, 2007). Na atualidade, essas diretrizes se encontram em renegociação. Enquanto a regulamentação dos ensaios clínicos nos EUA é harmonizada em nível federal pela Administração de Alimentos e Drogas (FDA), na Europa, ainda que exista a harmonização normativa supranacional descrita, na prática, os ensaios se desenvolvem segundo as normas das autoridades nacionais competentes, a exemplo da MHRA no RU (CHOWDHURY; WESSEL, 2012).

Forças opostas se encontram em contestação. Cada vez mais, caminhos alternativos às diretivas gerais, e mais rápidos, se impóem no marco das práticas na UE (EICHLER et al., 2014). Ainda assim, isso gera uma permanente tensão entre a regulamentação dominante e as condiçôes de isenção ou exceção. 


\section{Flexibilidades nas licenças dos ensaios clínicos}

Algumas das modificações em relação às ATMP formam parte da legislação farmacológica da UE, mas outras, são específicas da medicina regenerativa e promovem um sistema normativo híbrido e diversificado (FAULKNER, 2016). Em geral, a grande diferença que se estabeleceu na UE, é aquela entre a forma de regulamentar a TC industrial nas empresas e a não industrial nos hospitais.

Dentre as flexibilidades de licenças para os produtos farmacológicos na UE, encontram-se: a) a aprovação condicional das TC, para as doenças raras, consideradas órfấs; licenças para os ensaios em TC aplicadas com renovação anual e utilizadas para um número menor de pacientes em situações de emergência. Em geral, isso implica que se omite a fase II dos ensaios clínicos convencionais e desenvolve-se a fase IV, quando o produto já está no mercado. Esse tipo de licença corresponde aproximadamente entre $10 \%$ e $20 \%$ das drogas aprovadas; b) as licenças por circunstâncias excepcionais, utilizadas quando se carece de uma informação concluinte sobre o assunto da inovação; c) a avaliaçáo acelerada de produtos, que gerem grandes benefícios à saúde pública, tenha uma visão inovadora e se ajustem às expectativas dos pacientes de um progresso tecnológico rápido.

A EMA, em 2014, adotou esses caminhos adaptativos de licenças - as "licenças adaptativas para novas drogas" - sem modificar o marco de referência regulatório anterior, o que não deixa de ser uma forma de aceitar a pressão social baseada na expansão do setor e na necessidade de acesso rápido dos pacientes às TC (BOSELEY, 2011).

Dentre as licenças que não surgem diretamente do sistema reformulado de regulação dos produtos farmacológicos, há no RU um tipo de licença, chamada de "isenção hospitalar" - segundo o Artigo 28 (2) da ATMP - que envolve poucos casos de pacientes. Até 2014, existiam 88 licenças desse tipo e são consideradas como uma forma de transição entre uma TC em experimentação e a sua aprovação centralizada na UE como ATMP (SCHNITGER, 2014).

A isenção hospitalar é bastante controversa e é aplicada de modo muito heterogêneo entre os Estados Membros da UE. Os críticos consideram que ela produz uma competência injusta, promove um mercado fragmentado e que também gera dúvidas em relação à segurança dos pacientes recrutados nos hospitais (IVASKIENE et al., 2017). Debate-se sobre a aplicação para usos não homólogos das TC testadas, 
acerca de qual seria o número limite de pacientes para a utilização de igual protocolo clínico, em relação à qual é o número mínimo de sítios de manufatura não industrial autorizados, assim como, o fato da medida ter sido caracterizada como prática 'não de rotina' (CORBETT et al., 2017). Alguns dos maiores críticos têm surgido da comunidade científica e médica e, às vezes também, das associaçôes de caridade e de pacientes que encontram diminuídos os benefícios para seus associados (SALTER et al., 2017). Além disso, essa regulação é limitante num outro sentido, porque não permite o transporte de materiais através das fronteiras nacionais.

Uma segunda medida normativa para os ensaios no RU, o "esquema especial", se assemelha a um dos padróes que funciona para os produtos farmacológicos. Implica numa solicitação bona fide de uma terapia por um profissional responsável, para o tratamento de um paciente individual e utiliza-se um produto com uma licença de manufatura estandardizada. $\mathrm{O}$ uso dessa flexibilidade tem sido mais frequente que aquele da "isenção hospitalar" (HOUSES OF PARLIAMENT, 2017).

Uma terceira prática flexível em uso no RU consiste na designação de uma TC como "dispositivo médico", e que se rege pela Diretiva da UE dos Dispositivos Médicos do ano 2001 e com uma última alteração no ano 2007 (EUROPEAN COMMISSION, 2017). Se aplica quando não se precisa de uma manipulação substantiva dos materiais para obter o produto e quando o modo de ação da TC não aparece totalmente predefinido, por exemplo, na utilização de sistemas tecnológicos fechados de centrifugação para isolar as células-tronco.

Uma medida flexível menos explorada é aquela do sistema de "preços baseados no valor" ou de "avaliação baseada no valor" que é um tipo de quarta entrada das TC no mercado, através da HTA e da NICE (National Institute for Health and Care Excellence). A norma define o valor das drogas no longo prazo no RU e mede seus benefícios, agregando uma categoria extra - a de "impacto social amplo" - as já utilizadas dentro do NICE: "carga da doença" e "melhora terapêutica" (NICE, 2014, p. 7). O novo critério considera: a perdida na capacidade da pessoa de se engajar na sociedade devido à sua doença. Mas esta licença tem encontrado falta de apoio público e também tem sido bem menos utilizada devido às dificuldades na sua medição.

Uma última isenção aplicável no RU é aquela chamada de "pedido de investimento do paciente individual" (individual funding request) que é disponível a clínicos individuais, nos casos de necessidade excepcional e para os pacientes com doenças 
raras. O status de medicinas órfẫs ou ultra órfẫs possibilita várias isençôes impositivas e outorga um monopólio de dez anos sobre a produção (HYRY et al., 2015).

Algumas destas práticas regulatórias flexíveis foram apresentadas na Estratégia para as Ciências da Vida do Governo (DEPARTMENT OF HEALTH, 2011), desenhada para promover o processo de translação de resultados das TC do laboratório à clínica. Se enquadra dentro do Esquema de Acesso Rápido à Medicina, referido às medicinas sem autorização prévia de mercado para as doenças graves que comprometem a vida (MEDICAL HEALTH RESEARCH AUTHORITY, 2014).

Esse esquema adquiriu status completo dentro da EMA em 2015, pela liderança pioneira do RU, e promete ser uma futura política de grande peso na região. Foi avaliada positivamente pelo RAND Europa - uma organização independente que promove a pesquisa - por facilitar um processo renovado de melhoras, ajuda a compartilhar os riscos associados entre os diferentes estamentos decisórios, colabora na expansão dos processos de interconexão entre instituiçôes relevantes e contribui a melhorar as falhas de mercado (PARRIS et al., 2016).

No RU, esse esquema regulatório é coordenado pelo MHRA, o NICE e os serviços especializados do sistema público de saúde (NHS). Dentro desse esquema, a primeira designação de um produto celular pelo MHRA foi aprovada no ano de 2014 para o tratamento do câncer.

Com essas normas flexíveis se simplifica, até certo ponto, o processo regulatório para os ensaios clínicos da terapia celular no RU, outrora considerados pouco acessíveis em nível global. Mas apresenta-se ainda uma tensão considerável entre os processos para a autorização dos produtos no mercado, os requisitos de adoção no sistema público de saúde e as decisôes de reembolso de custos aos produtores e usuários - sendo que os usuários têm uma crescente influência nas decisóes em saúde coletiva (SALTER et al., 2017).

Os últimos constituem os dois temas mais polêmicos na atualidade e segundo se reflete em três informes recentes sobre a medicina regenerativa no RU, como são: o da Casa dos Lordes de 2013, o do Grupo de Expertos em Medicina Regenerativa do ano 2014 e o da Casa dos Comuns do ano 2017 (HOUSE OF LORDS, 2013; REGENERATIVE MEDICINE EXPERT GROUP, 2014; HOUSE OF COMMONS, 2017). Por exemplo, o primeiro informe, criticava a escassa receptividade do NHS na provisão de terapias regenerativas e recomendava que o Departamento de Saúde se encarregue de formar um Grupo de Expertos 
em Medicina Regenerativa, integrado por representantes de todos os grupos de interesse, para assessorar o NHS com uma estratégia nessa direção. No último informe referido, recomenda-se também, uma maior interação com a indústria para a manufatura das terapias avançadas, assim como, a revisão do uso das "isençôes hospitalares". Argumentava-se que se deveriam criar incentivos adequados para estimular no NHS a inovação em medicina regenerativa e uma maior participação dos médicos, designar a medicina regenerativa como parte da estratégia do NHS em medicina personalizada, promover novos sistemas normativos rápidos para a prestação de serviços e desenhar modelos de reembolso de gastos através da cadeia total de valor: academia-manufatura-clínica.

\section{Reflexões para a Saúde Coletiva}

Desde aproximadamente as duas últimas décadas, o RU e a UE têm considerado as pesquisas e terapias celulares como uma janela de oportunidade para se colocar ainda mais na fronteira tecnológica global. Esse processo baseia-se em uma evolução dinâmica das visôes que configuram a produção das TC e organizam as relaçôes sociais. $\mathrm{Na}$ expansão da área, têm sido dominantes diferentes grupos de interesse segundo mudam as trajetórias de inovaçáo adotadas. No momento chave da manufatura global das TC e de sua gradual incorporação nos sistemas públicos de saúde, se faz imperativa a discussão do seu papel no atendimento da saúde coletiva.

Em alguns casos, a própria pressão dos cidadãos organizados para satisfazer suas necessidades em saúde - como demostrado por exemplo, por Salter et al. (2015) - tem levado a simplificar a governança e a flexibilizar as regulaçóes em ensaios clínicos em terapia celular na UE e no RU. Apesar disso, discute-se na literatura associada, como estabelecer um equilíbrio entre o reconhecimento dessas demandas sociais em saúde e a oferta de soluçôes viáveis (GURA, 2013; SILVERTOWN, 2009), assim como, em relação às diferentes formas de caracterizar o novo papel que cumpre a ciência cidadã - ou seja, o envolvimento de voluntários nos projetos de pesquisa científica em níveis comunitário ou global (EGE, 2015). Debate-se também, a formulação de patamares adequados de qualidade e segurança das TC, em um setor onde predominam formas de ordenamento do conhecimento científico nem tanto baseado no cálculo técnico e probabilístico, mas também no paradigma da incerteza, ou seja, no debate técnico e ético sobre os limites e as possibilidades do conhecimento (GOTTWEISS et al., 2009). 
Por exemplo, colocam-se questôes sociais, econômicas e éticas diferenciais no caso das TC autólogas versus as alógenas. As primeiras, são "customizadas ao cliente" e envolvem capacidades médicas especializadas, assim como custos maiores, e a reformulação ou distanciamento da dimensão coletiva da saúde (DICKENSON, 2016). Neste caso, os reembolsos dos gastos a produtores e usuários se complicam pelo escasso número de pacientes atendidos e os altos custos envolvidos. As segundas, potencialmente de uso amplo, ainda dependem da existência de plataformas tecnológicas e manufaturas industriais em formação; de sistemas de transporte, de infraestrutura e manipulação hospitalar, construídas com base em novos parâmetros de purificação, armazenagem, segurança e descontaminação; de recursos financeiros substantivos e de especialistas para o desenvolvimento de estudos clínicos específicos, fase I a III. Eles tendem a ser escassos nos países emergentes como sinalizam Bortz et al. (2019) para o caso da Argentina. A entrada mais permanente nos sistemas públicos de saúde da medicina regenerativa requer do involucramento especializado de novos atores: médicos especialistas e de apoio, técnicos, enfermeiras e pessoal administrativo que - como constata-se em alguns trabalhos na área - muitas vezes, carecem da formação adequada para lidar com terapias e drogas avançadas (ex. HWANG; SLEEBOOM-FAULKNER, 2014).

Além disso, o processo de adoção nos sistemas públicos de saúde precisa de um compromisso de renovação substantiva das suas formas de operação e de gestão e, pelo tanto, de uma revisão nos níveis de aceitação das diferentes comunidades vis-à-vis as medicinas e protocolos tradicionais. No processo, podem-se gerar novas assimetrias sociais na área da saúde e/ou o aprofundamento das existentes, ex. entre especialistas e não especialistas, entre promotores de ensaios clínicos e profissionais da saúde, entre o pessoal da manufatura das TC e o pessoal do hospital (REGENERATIVE MEDICINE EXPERT GROUP, 2014).

Além disso, o fato de que nos ensaios clínicos alógenos prefere-se não se incluir pacientes mulheres em idade fértil, pode também provocar, não apenas o desconhecimento científico e técnico dos efeitos diferenciais das TC e drogas avançadas por gênero, mas também, discriminar as mulheres nas suas futuras aplicaçôes (WEBSTER; HADDAD; WALDBY, 2011). Uma possível discriminação das mulheres nos futuros tratamentos constitui uma contradição, em um área onde a sua função é central, como únicas doadoras de óvulos e principais produtoras de 
embriôes, base de alguns das TC em experimentaçấo, como têm sido discutido, entre outras acadêmicas feministas, por Franklin (2019).

A flexibilidade na regulamentação dos ensaios clínicos celulares também pode produzir resultados contraditórios. Por um lado, poderia permitir um melhor e mais rápido acesso às terapias a doentes selecionados, mas pelo outro, poderia provocar uma maior desproteção dos pacientes em relação a seus potenciais efeitos adversos, e, em especial, devido à proposta atual de compartilhar os riscos entre todos os atores envolvidos (FAULKNER, 2016). Não deveria descartar-se também a análise de como as flexibilidades regulatórias poderiam contribuir a criar mercados paralelos na adoção das medicinas avançadas, como alguns autores exemplificam, e devido às variaçôes de interpretaçóes que as normas possibilitam entre os profissionais responsáveis, através da repetição indeterminada dos ensaios clínicos com um número reduzido de paciente e pelas formas não homologáveis da utilização das TC experimentais (ex. CUENDE et al., 2014; IVASKIENE et al., 2017).

A tensão entre a tendência aos processos de harmonização legislativa e regulatória global na medicina regenerativa e aquela da diversificação, não tem ainda um horizonte claro de resolução, como têm sido demostrado no trabalho pioneiro de Van Zwanenberg et al. (2011). Mas a inter-relação entre tendências, parece apontar uma transição gradual do que define-se como 'bom', 'desejável' e 'possível' - presente na abordagem teórica de Jasanoff; Kim (2009) - para a criação de novos patamares regulatórios fundamentados na mudança das visóes sociais dominantes.

A resistência dos atores sociais relevantes tem se manifestado construindo espaços regulatórios alternativos, como no caso de novas associaçóes profissionais internacionais: ICMS (2011) e ISCT (2015). Esses espaços atingem de modos diferenciais a saúde coletiva das populaçóes e dos pacientes mais vulneráveis, em especial, nos países emergentes. A consolidação dos arcabouços regulatórios harmonizados ou diversificados se veem dificultados também, pelos muitos vazios de informação na área que precisam, por exemplo, do registro centralizado de dados, confiáveis e acessíveis em nível global, com informaçôes referentes à quantidade de ensaios clínicos, de terapias e drogas celulares em circulação, da sua distribuição nos diferentes países, dos totais reais - e não apenas estimados - de pacientes usuários e de dados fidedignos dos resultados dos tratamentos, segundo colocam autores como Isasi; Knopper (2009). 
No caso dos PE, com recursos mais escassos atribuídos à saúde, precissamse também de políticas públicas que estabeleçam um equilibrio dinâmico nos orçamentos nacionais: entre as atribuiçôes de recursos para atender a demanda em doenças endêmicas e infecciosas vis-à-vis em doenças não infecciosas, as quais estão destinadas principalmente às medicinas regenerativas. Se consideram-se alguns dos problemas sociais que enfrentam os $\mathrm{PE}$ em termos do acesso da população a produtos e serviços básicos, além do fato de que, em geral nesses países o investimento em TC costuma ser principalmente público, se abre o debate de se a área de medicina regenerativa deveria ou não definir-se como umaárea tecnológica estratégica, segundo discute-se em alguma da literatura relevante na América Latina (RODRIGUEZMEDINA et al., 2019). Por outro lado, o uso de recursos financeiros e humanos para a construção de um arcabouço centrado apenas na pesquisa em células tronco em alguns $\mathrm{PE}$, os deixaria sujeitos à importação de materiais de manufatura celular e medicamentos eventuais produzidos pela grande indústria farmacêutica global, e assim, poderia vir a encarecer ainda mais a adoção da medicina regenerativa pelos sistemas públicos de saúde. Essa situação potencial tem sido fundamentada, por exemplo, por cientistas brasileiros especialistas, como Mayana Zatz ( 2011 ), Steven Rehen e Bruna Paulsen ( 2007) e em alguns trabalhos acadêmicos ( ex. TEIXEIRA ZORZANELLI, R. et al., 2017).

Para que o novo referencial científico e médico seja melhor conhecido e aceito socialmente, se requer um debate público em assuntos específicos da MR, um diálogo inclusivo e uma divulgação mais frequênte e precissa, através da mídia, do estágio dos avanços clínicos na área. O desenho de regulação e fiscalização focada no aumento da transparência nas práticas clínicas nos consultórios e hospitais privados também constituem fatores centrais nesse processo.

A exclusão do público amplo, sua inclusão apenas seletiva e/ou a falta de políticas sistemáticas de engajamento público têm sido estratégias frequentes em muitos países (ex. ACERO, 2011; GUIVANT; MACNAGHTEN, 2011). A escassez do diálogo público facilita práticas ilícitas, já significativamente documentadas na literatura associada, como são o desenvolvimento de ensaios clínicos não autorizados, a expansão na aplicação de TC experimentais (MCMAHON, 2014) e do turismo médico (COHEN, 2012). Essas irregularidades estão ocorrendo em nível global, em alguns PE como a China e a Coréia do Sul, mas também em países europeus, com casos documentados, por exemplo, na Itália, no Reino Unido, na Suecia e na 
Alemânia, e alguns deles judicializados. Têm sido complexo, até agora, estabelecer mecanismos regulatórios uniformes e obrigatórios entre os países membros da UE para prevenir a sua ocorrência, ainda que existam associaçóes internacionais baseadas na Europa com iniciativas internacionais nessa direção, como a: International Society for Stem Cell Research (ISSCR).

Em relação a essas práticas irregulares, se requer também desenvolver uma maior consciência pública global como ilustram autores vários (ex. EINSENDEL; ADAMSON, 2012). As políticas públicas nacionais e internacionais deveriam se desenhar através do diálogo amplo com diferentes 'públicos' e com foco em uma real compreensão social dos fatores sociopolíticos e biológicos envolvidos nos materiais, métodos e aplicações da TC, com fins de que a preocupação com o cuidado da saúde coletiva se torne uma realidade em não apenas uma simples intenção.

\section{Referências}

ACERO, L. Pesquisas e terapias com células-tronco: governança, visóes sociais e o debate no Brasil. Rio de Janeiro: Ed. E-Papers, 2011.

BERMAN, H.; SCHIFF, P. Global Legal Pluralism, 80 Southern California Review. Princeton Law and Public Affairs, v. 1155, n. 08-001. Princeton: Princeton Press, 2007.

BLASIMINNE, A.; RIAL-SEBBAG, E. Regulation of Cell-Based Therapies in Europe: Current Challenges and Emerging Issues. Stem Cells Development, v. 22, n. 1, p. 14-19, 2013.

BORTZ, G. et al. Construção das terapias com células-tronco na Argentina: regulação, gestão de riscos e políticas de inovação. Sociologias [online], v. 21, n. 50, p. 116-155, 2019. Disponível em: <http://www.scielo.br/scielo.php?script=sci_arttext\&pid=S1517-45222019000100116\&lng $=$ en\&nrm=iso>. Acesso em: 12 jun. 2019.

BOSELEY, S. New medical research body urged to speed up drug trial approvals. The Guardian, April 4, 2011. Disponível em: <http://www.guardian.co.uk/>. Acesso em: 12 nov. 2018.

CHOWDHURY, N.; WESSEL, R. A. Conceptualizing Multilevel Regulation in the EU: A Legal Translation of Multilevel Governance? European Law Journal, v. 18, n. 3, p. 335-357, 2012. COHEN, G. How to regulate medical tourism (and why it matters for bioethics). Developing World Bioethics, v. 12, n.1, p. 9-20, 2012.

CORBETT, M. et al. Innovative regenerative medicines in the EU: a better future in evidence? BMC Medicine, v. 15, p. 49, 2017.

CUENDE, N. et al. The puzzling situation of hospital exemption for advanced therapy medicinal products in Europe and stakeholders' concerns. Cytotherapy, v. 16, p. 1597-1600, 2014. 
DEPARTMENT OF HEALTH. Taking Stock of Regenerative Medicine in the United Kingdom. London: Dept. of Health, Department for Business, Innovation \&Skills (BIS), Office for Life Sciences, 2011.

DICKENSON, D. Me Medicine vs. We Medicine: Reclaiming Biotechnology for the Common Good. New York: Columbia University Press, 2016.

EICHLER, H-G. et al. From Adaptive Licensing to Adaptive Pathways: Delivering a Flexible Life-Span Approach to Bring New Drugs to Patients. Clinical Pharmacology and Therapeutics, v. 97, n. 3, p. 234-246, 2014.

EINSENDEL, E. F.; ADAMSON, H. Stem cell tourism and future stem cell tourists: policy and ethical implications. Developing World Bioethics, v. 12, n. 1, p. 35-44, 2012.

EUROPEAN COMMISSION. Regulation (EU) 2017/745 of the European Parliament and the Council on medical devices. Brussels: European Commission, 2017. Disponível em: <http:// www.data.europa.eu/eli/reg/2017/745/oj>. Acesso em: 22 nov. 2018.

EUROPEAN GROUP ON ETHICS IN SCIENCE AND NEW TECHNOLOGIES (EGE). Opinion $n^{\circ} 29$. The ethical implications of new health technologies and citizen participation. Brussels: European Commission, 2015. Disponível em: <https://publications.europa.eu/en/ publication-detail/-/publication/e86c21fa-ef2f-11e5-8529-01aa75ed71a1/language-en/formatPDF/source-77404221>. Acesso em: 12 jan. 2019.

EUROPEAN MEDICINES AGENCY. Concerns over unregulated medicinal products containing stem cells, 2010. Disponível em: <http://www.ema.europa.eu/docs/en_GB/document_library/ Public_statement/2010/04/WC500089472.pdf>. Acesso em: 3 fev. 2019.

FAULKNER, A. Opening the gateways to market and adoption of regenerative medicine? The UK case in context. Regenerative medicine, v. 11, n. 3, p.321-330, 2016.

FOLEY, L. et al. Supply chain management in regenerative medicine manufacturing. In: D. SPATH, D. (Ed.). 21st International Conference on Production Research: Innovations in Product and Production. Stuttgart: Fraunhofer IRB Verlag, 2011.

FRANKLIN, S. Analogic return: the reproductive life of conceptuality. Theory, Culture \& Society, v. 3 p. 243-261, 2014. Disponível em: <http://doi.org/10.1177/0263276413510953>. Acesso 4 jun. 2019.

GUIVANT, J.; P. MACNAGHTEN. O mito do consenso: uma perspectiva comparativa sobre governança tecnológica. Ambiente \& Sociedade, v. 14, n.2, p. 89-104, 2011.

GOTTWEISS, H. et al. The Global Politics of Human Embryonic Stem Cell Science: Regenerative Medicine in Transition. London: Palgrave/MacMillan, 2009.

GURA, T. Citizen Science: Amateur experts. Nature, v.496, p.259-261, 2013. 
HOEY, R. The EU Clinical Trials Directive: 3 years on. The Lancet, v. 369, n. 9575, p. $1777-$ 1778, 2007.

HOGARTH, S.; SALTER, B. Regenerative medicine in Europe: global competition and innovation governance. Special Report. Regenerative Medicine, v. 5, n. 6, 2010.

HOUSE OF COMMONS. Science and Technology Committee. Regenerative medicine. Fifteenth Report of Session 2016-17. London: House of Commons. 2017. Disponível em: <http://www.publications.parliament.uk/pa/cm201617/cmselect/cmsctech/275/275.pdf>. Acesso em: 4 jan. 2019.

HOUSE OF LORDS. Science and Technology Committee on Regenerative Medicine. London: House of Lords, Stationery Office, 2013. Disponível em: <http://www.publications.parliament. uk/pa/ld201314/ldselect/ldsctech/23/23.pdf>. Acesso 6 jan. 2019.

HOUSES OF PARLIAMENT. Regulating Advanced Therapies. Postnote. Parliamentary Office of Science and Technology, n. 567, p. 1-5, 2017. Disponível em: <http://www.file:///D:/ Downloads/POST-PN-0567.pdf>. Acesso em: 21 jan. 2019.

HWANG, S.; SLEEBOOM- FAULKNER, M. Bioethical governance in South Korea: tensions between bottom-up movements and professionalization, and scientific citizenship. East Asian Science, Technology and Society: An International Journal, v. 8 n. 2, p. 209-228, 2014.

HYRY, H. et al. Compassionate use of orphan drugs. Orphanet, Journal of Rare Diseases, v. 10, p. 100, 2015.

INTERNATIONAL CELLULAR MEDICINE SOCIETY. Minimum Standards for the Practice of Cell Based Medicine, 2011. Disponível em: <http://www.cellmedicinesociety.org/ attachments/370_Minimum\%20Standards\%20for\%20the\%20Practice\%20of\%20Cell\%20 Based\%20Medicine.pdf>. Acesso em: 6 nov. 2018.

INTERNATIONAL SOCIETY FOR CELLULAR THERAPY. Presidential Task Force on the Use of Unproven Cellular Therapies: reference guide. 2015. Disponível em: <http://www. celltherapysociety.org/?page=PTF2015>. Acesso em: 22 jan. 2019.

INTERNATIONAL SOCIETY FOR STEM CELL RESEARCH. Guidelines for Stem Cell Research and Clinical Translation, a Report from the International Society for Stem Cell Research. London: ISSRC, 2016. Disponível em: <http://www.isscr.org/docs/default-source/all-isscrguidelines/guidelines-2016/isscr-guidelines-for-stem-cell-research-and-clinical-translationd671 19731dff6ddbb37cff0000940c19.pdf?sfvrsn=4>. Acesso em: 7 dez. 2018.

ISASI, R. Registration of stem cell-based clinical trials: A scientific and ethical imperative. In: GENETICS POLICY INSTITUTE (Ed.). World Stem Cell Report 2009, p. 15-20. Florida: Genetics Policy Institute, 2009. 
IVASKIENE, T. et al. Hospital Exemption for Advanced Therapy Medicinal Products: Issue in Application in the European Union Member States. Current Stem Cell Research \& Therapy, v. 12, p. $45-51,2017$.

JASANOFF, S.; KIM, S. Containing the Atom: Sociotechnical Imaginaries and Nuclear Power in the United States and South Korea. Minerva, v. 47, p. 119-146, 2009.

KOPPERS, B.; ISASI, R. Stem cell banking: between traceability and identifiability. Genome Medicine, v. 2, p. 73, 2010.

MACIULAITIS, R. et al. Clinical Development of Advanced Therapy Medicinal Products in Europe: Evidence That Regulators Must Be Proactive. Molecular Therapy, v. 20, n. 3, p. 479482, 2012.

MCMAHON, D.; THORSTEINSDOTTIR, M. Pursuing endogenous high-tech innovation in developing countries: A look at regenerative medicine innovations in Brazil, China and India. Research Policy, v. 42, p.965-974, 2013.

MCMAHON, D. The global industry for unproven stem cell interventions and stem cell tourism. Tissue Engineering and Regenerative Medicine, v. 11, n.1, p. 1-9, 2014.

MARTIN, P. et al. From bedside to bench? Communities of promise, translational research and the making of blood stem cells. Science as Culture, v. 17, n. 1, p. 29-41, 2008.

MEDICAL HEALTH RESEARCH AUTHORITY. Advanced Therapy Medicinal Products: regulation and licensing, 2015. Disponível em: <http://www.ec.europa.eu/health/human-use/ legal-framework_en>. Acesso em: 5 dez. 2018.

MEDICAL HEALTH RESEARCH AUTHORITY. Early Access to Medicines Scheme, 2014. Disponível em:: <http://www.mhra.gov.uk/Howweregulate/Innovation/ EarlyaccesstomedicinesschemeEAMS/index.htm>. Acesso em: 12 nov. 2018.

MASON, C.; DUNNILL, P. A brief definition of regenerative medicine. Regenerative Medicine, v. 3, n 1, p. 2-5, 2008.

NATIONAL INSTITUTE OF HEALTH. Guidelines for Stem Cell Research, Washington: NIH, 2009. Disponível em: <http://www.stemcells.nih.gov/ policy/2009 guidelines.htm>. Acesso em: 18 nov. 2018.

NATIONAL INSTITUTE FOR HEALTH AND CARE EXCELLENCE. Value Based Assessment of Health Technologies. Consultation Paper, London: NICE, Centre for Health Technology Evaluation, 2014.

O'DOWD, A. Health Research Authority outlines plans to improve transparency of UK clinical research. BMJ, v. 347, 2013. Disponível em: <http://www.bmj.com/content/347/bmj. f6555>. Acesso em: 18 nov. 2018. 
PARRIS, S. Galvanizing the NHS to adopt innovation: The feasibility and practicality of recommendations from the interim report of the Accelerated Access Review. RAND Europe Reports, 2016. Disponível em: <http://www.rand.org/randeurope/publications/health.2.html>. Acesso em: 24 nov. 2018.

REHEN, S.; PAULSEN, B. Células-tronco: o que são? Para que servem? Rio de Janeiro: Vieira \& Lent, 2007.

REGENERATIVE MEDICINE EXPERT GROUP. Building on our own potential: a UK pathway for regenerative medicine. A report from the Regenerative Medicine Expert Group, 2014. London: House of Lords. Disponível em: <http://www.assets.publishing.service.gov.uk/ government/uploads/system/uploads/attachment_data/file/415919/build-on-potential.pdf>. Acesso em: 15 jan. 2019.

RESEARCH MARKET. Global Stem Cells Market Research Report 2018. Markets Insider, 2018. Disponível em: <http://markets.businessinsider.com/news/stocks/global-stem-cellsmarket-research-report-2018-1027517832>. Acesso em: 5 jan. 2019.

RODRIGUEZ-MEDINA, L. et al. International Ties at Peripheral Sites: Co-producing Social Processes and Scientific Knowledge in Latin America. Science as Culture, June, 2019. Disponível em: <http://www.tandfonline.com/doi/abs/10.1080/09505431.2019.1629409> Acesso em: 12 jun. 2019.

ROSEMANN, A. Medical innovation and national experimental pluralism: insights from clinical stem cell research and applications in China. Biosocieties, v. 8, n. 1, p. 58-74, 2013.

- Standardization as situation-specific achievement: regulatory diversity and the production of value in intercontinental collaborations in stem cell medicine. Social Science \& Medicine, v. 122, p. 72-80, 2014.

SALTER, B. et al. Governing new global health-care markets: the case of stem cell treatments. Journal of New Political Economy, v. 22, n. 1, p. 76-91, 2017.

. Hegemony in the marketplace of biomedical innovation: consumer demand and stem cell science, Social Science \& Medicine, v. 131, p. 156-163, 2015.

SCHNITGER, A. The Hospital Exemption, a regulatory option for unauthorized advanced therapy medicinal products. unpublished Master's thesis, Bonn: Bonn University, 2014.

SILVERTOWN, J. A new dawn for citizen science. Trends in Ecology and Evolution, v.9, p. 467-471, 2009.

SLEEBOOM-FAULKNER, M. et al. Comparing national home-keeping and the regulation of translational stem cell applications: An international perspective. Social Science \& Medicine, v. 153 , p. $240-249,2016$. 
TEIXEIRA ZORZANELLI, R. et al. Pesquisa com células-tronco no Brasil: a produção de um novo campo científico. História, Ciência e Saúde-Manguinhos, v. 24, n.1, p. 129-144, 2017. VAN ZWANENBERG, P. et al. Regulating technology: International harmonization and local realities. London: Routledge/ ESRC, 2011.

WEBSTER, A.; ERIKSSON, L. Governance-by-standards in field of stem cell research: managing uncertainty in the world of "basic innovation". New Genetics and Society, v. 27, n. 2, p. 99-11, 2009.

WEBSTER, A.; HADDAD, C.; WALDBY, C. Experimental heterogeneity and standardization: Stem Cell products and the clinical process. Biosocieties, v.6, n. 4, p.401-419, 2011.

ZATZ, M. Genética: escolhas que nossas avós não faziam. São Paulo: Editora Globo, 2011.

\section{Nota}

${ }^{1}$ No ano de 2017, o mercado global de células-tronco (CT) estava avaliado em 5.17 bilhôes de dólares e estima-se que cresceria a 9.03 bilhóes de dólares em 2023, resultante em um aumento de $9.74 \%$ entre 2017 e 2023 (RESEARCH MARKET, 2018). 


\section{Abstract}

Global Governance, Flexible Regulation and Clinical Trials in Regenerative Medicine in the United Kingdom and the European Union

Regenerative medicine is at present in a stage of development of clinical trials in cell therapies (CT), their manufacture and gradual adoption by health systems. However, there are several gaps and contradictions in governance and regulation in the area and the main aim of this article is their discussion within global trends, as these processes remain still illresolved while substantively affecting collective global health. The text focuses on an analysis of prevailing processes in clinical trials with CT by two leading actors, the United Kingdom, and the European Union, and is based upon bibliographical and content analyses. The article concludes with a discussion of the main advantages and disadvantages for collective global health of the transition from a conventional scientific model to test the new therapies to, eventually, one based on medical or clinical innovation. The latter proceeds from the pre-clinical research phase with animals to clinical trials with small groups of patients and subsequently, to the entrance of cell therapies into the market. Often this model is associated to flexible regulations, to be illustrated in the article, which are specifically designed to diminish time-lags between therapy development and its full application.

> Keywords: cellular therapy; clinical trials; governance; international policies; regenerative medicine; flexible regulation. 